\title{
Pengaruh Penggunaan Metode Experiential Learning terhadap Hasil Belajar Anatomi Bagi Mahasiswa Fakultas Kedokteran Universitas Muhammadiyah Semarang
}

\author{
Mega Pandu Arfiyanti*, Arum Kartika Dewi** \\ *Bagian Ilmu Kedokteran Dasar, Fakultas Kedokteran Universitas Muhammadiyah Semarang \\ ** Bagian Ilmu Kedokteran Dasar, Fakultas Kedokteran Universitas Muhammadiyah Semarang \\ Koresponden: \\ dr. Mega Pandu Arfiyanti, M.MedEd \\ Bagian Ilmu Kedokteran Dasar, Fakultas Kedokteran Universitas Muhammadiyah Semarang \\ Jl. Kedungmundu Raya 18, Semarang. Telp. 024-76740295 \\ Email: megaarfiyanti@gmail.com
}

\begin{abstract}
ABSTRAK
Anatomi merupakan ilmu dasar yang harus dikuasai oleh mahasiswa Fakultas Kedokteran sebagai dasar melakukan pemeriksaan fisik dan penalaran klinis. Pemahaman mahasiswa akan ilmu anatomi masih kurang karena menganggap anatomi sangat susah dipelajari. Metode pembelajaran aktif anatomi diperlukan untuk meningkatkan pemahaman mahasiswa. Penelitian ini bertujuan mengetahui pengaruh penggunaan metode experiential learning terhadap hasil belajar anatomi mahasiswa. Penelitian ini merupakan penelitian eksperimental pretest posttest design dengan sampel seluruh mahasiswa tahun pertama FK Unimus yang dibagi menjadi kelompok kontrol dan perlakuan dengan randomised sampling. Mahasiswa kelompok perlakuan diajarkan anatomi dengan metode experiential learning, sedangkan kelompok kontrol dengan metode konvensional. Data yang diambil adalah rerata selisih nilai pretest posttest kelompok kontrol dan kelompok perlakuan. Dari 110 mahasiswa hanya 94 mahasiswa yang mengikuti seluruh protokol penelitian yang terdiri dari 47 mahasiswa kelompok kontrol dan 47 mahasiswa kelompok perlakuan. Berdasarkan uji independent $\mathrm{t}$ test di dapatkan hasil sig (2-tailed) 0.000 yang artinya metode experiential learning memiliki pengaruh terhadap hasil belajar anatomi. Metode experiential learning efektif digunakan untuk meningkat hasil belajar anatomi mahasiswa Fakultas Kedokteran Universitas Muhammadiyah Semarang.
\end{abstract}

Kata kunci: Experiential learning, anatomi, pendidikan kedokteran

\section{ABSTRACT}

Anatomy is a basic science that must be mastered by medical students as a basis for conducting physical examination and clinical reasoning. Students' understanding of anatomy is still lacking because they consider anatomy very difficult to learn. Active anatomy learning methods are needed to improve student understanding. This study aims to determine the effect of using experiential learning methods on student anatomy learning outcomes. This research is an experimental pretest posttest design with a sample of all first-year Unimus medical students divided into control and experiment groups with randomized sampling. The experiment group students were taught anatomy by the experiential learning method, while the control group used the conventional method. The data taken is the average value difference between the pretest posttest of the control group and the treatment group. Of the 110 students only 94 students participated in the entire study protocol consisting of 47 control group students and 47 treatment group students. Based on the independent $t$ test, the results of the sig (2-tailed) 0,000 were obtained, which means that the experiential learning method had an influence on the results of anatomical learning. Experiential learning methods increase the anatomical learning outcomes of medical students in University of Muhammadiyah Semarang.

Keyword : experiential learning, anatomy, medical education 


\section{PENDAHULUAN}

Mahasiswa Kedokteran seharusnya memiliki pemahaman yang baik mengenai ilmu anatomi sebagai dasar pemahaman patofisiologi dan dasar untuk melakukan pemeriksaan klinis, namun bagi sebagian besar mahasiswa tahun pertama materi ini dianggap sebagai materi yang sangat menakutkan dan berisikan ilmu yang berat serta sulit dipahami. ${ }^{1,2,3,4}$ Kegagalan dalam pemahaman ilmu Anatomi bagi mahasiswa kedokteran dapat berdampak buruk bagi ketidaksiapan mahasiswa kedokteran dalam fase klinik. Anatomi di Fakultas Kedokteran Universitas Muhammadiyah Semarang diberikan melalui kuliah kelas besar dan praktikum, kegiatan diskusi dengan mahasiswa masih kurang interaktif. Selama 5 tahun terakhir tingkat kegagalan mahasiswa Fakultas Kedokteran Universitas Muhammadiyah Semarang dalam ujian anatomi cukup tinggi, yaitu sebanyak 80\%. Berdasarkan penelitian pendahuluan kepada dosen anatomi, dilaporkan bahwa terdapat motivasi yang rendah dari mahasiswa untuk belajar anatomi karena merasa anatomi susah untuk dipelajari.

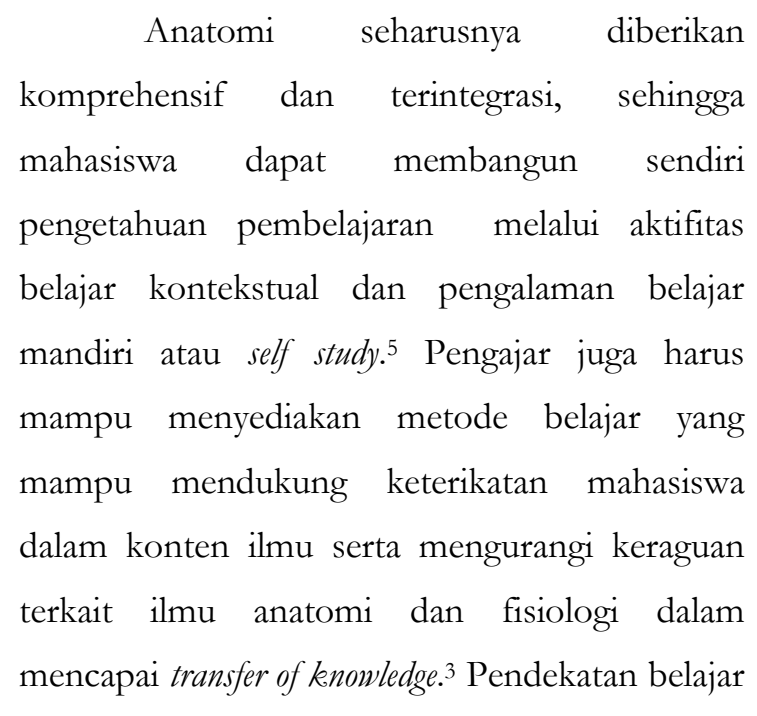

experiential learning dari Kolb direkomendasikan untuk diaplikasikan sebagai salah satu metode pembelajaran yang interaktif dengan penekanannya pada refleksi dan menempatkan siswa dalam kelompok belajar berdasarkan pengalaman.6,7,8 Sejalan dengan teori diatas, penulis mencoba merencanakan sebuah penelitian penerapan metode pembelajaran experiential learning untuk mengajarkan ilmu Anatomi pada mahasiswa tingkat pertama.

\section{METODE PENELITIAN}

Penelitian ini menggunakan desain eksperimental dengan Pretest Posttest Control Group Design. Sampel yang digunakan adalah mahasiswa tahun pertama Fakultas Kedokteran Universitas Muhammadiyah Semarang jumlah total 110 orang. Setiap mahasiswa diberi informed consent dan menandatangani surat persetujuan untuk mengikuti penelitian ini. Sampel penelitian dibagi secara randomised sampling menjadi kelómpok kontrol dan kelompok eksperimen. Kriteria inklusi penelitian ini adalah mahasiswa mengikuti protokol penelitian dari awal sampai akhir, serta mengerjakan pretest dan posttest. Soal pretest dan posttest anatomi sistem organa sensuum digunakan untuk mengukur kemampuan kognitif mahasiswa sebelum dan sesudah dilakukan penelitian.

Secara garis besar proses penelitian akan dilakukan melewati beberapa tahap pengumpulan data, yaitu pretest, proses pembelajaran, dan posttest. Pretest dilakukan oleh semua mahasiswa kelompok control dan kelompok eksperimen. Selanjutnya kelompok control akan mendapatkan materi anatomi 
sistem organa sensuum melalui kuliah dan praktikum selama 2 minggu. Kelompok control diberikan tugas membuat poster sistem organa sensuum dalam kelompok kecil dan kemudian mempresentasikan poster tersebut di hadapan dosen dan teman-temannya.

Kelompok eksperimen akan mendapatkan materi anatomi sistem organa sensuum melalui kuliah dan praktikum dengan metode experiential learning dalam waktu 2 minggu. Setelah diberikan pretest, kelompok eksperimen akan diminta untuk menggambar anatomi sistem organa sensuum dalam kelompok kecil (tahap concrete experience). Mahasiswa kemudian saling bertukar gambar yang sudah di buat lalu mereka saling mengoreksi gambar yang sudah dibuat oleh temannya, dari gambar tersebut di amati apa yang masih perlu ditambahkan dan mencocokkan gambar dengan manekin dan cadaver, pada tahap ini mahasiswa bisa melakukan refleksi dari hasil observasi selama praktikum dan mendapatkan umpan balik terstruktur dari dosen sebagai fasilitator (reflective observation). Dosen memfasilitasi proses diskusi mahasiswa dalam kelompok kecil. Mahasiswa kemudian diberikan kuliah anatomi sistem organa sensuum (abstract conceptualization). Mahasiswa diberikan tugas membuat poster anatomi sistem organa sensuum dalam kelompok kecil, kemudian poster tersebut di presentasikan di hadapan dosen dan temantemannya (active experimentation). Di akhir penelitian, mahasiswa di berikan soal posttest untuk mengetahui hasil belajar anatomi mahasiswa kelompok control dan kelompok eksperimen.
Data yang dikumpulkan adalah data untuk mengetahui hasil belajar mahasiswa yaitu data sebelum perlakuan (pretest), data setelah perlakuan (posttest). Data yang diperoleh dilakukan uji normalitas data untuk mengetahui apakah sampel berdistribusi normal atau tidak dengan Kolmogorov Smirnov. Data pretest dan posttest masing-masing kelompok di analisis dengan menggunakan paired $t$ test. Kemudian untuk membandingkan rerata selisih pretest dan posttest kedua kelompok di analisis dengan menggunakan independent $t$ test.

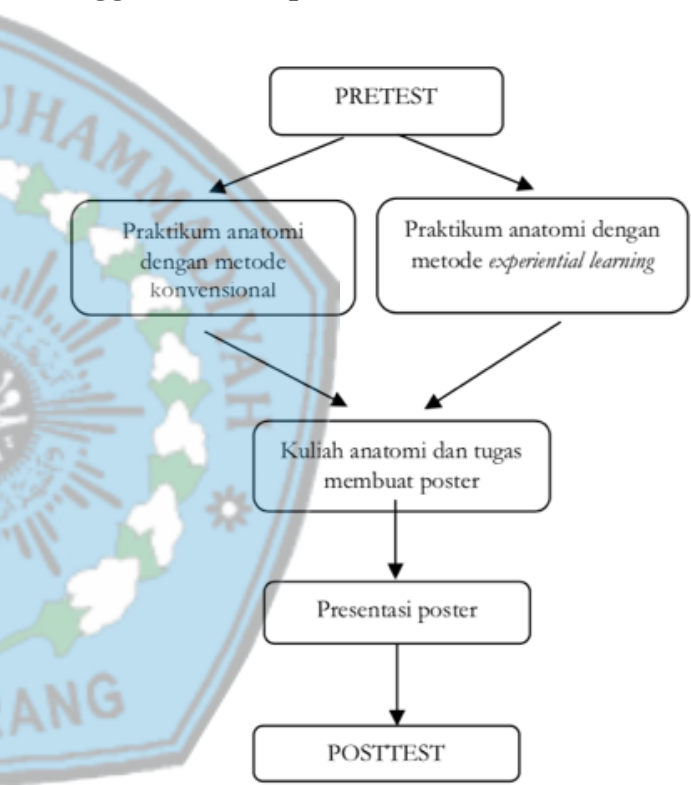

\section{Gambar 1.Cara kerja penelitian}

\section{HASIL PENELITIAN}

Dari total 110 mahasiswa tahun pertama FK Unimus hanya 94 mahasiswa yang mengikuti seluruh protokol penelitian. Dari 94 mahasiswa tersebut dibagi menjadi kelompok kontol 47 mahasiswa dan kelompok perlakuan 47 mahasiwa. Hasil pretest dan posttest kedua kelompok di uji normalitas data dengan uji Kolmogorov Smirnov didapatkan nilai sig pretest kelompok kontrol 0.200 dan kelompok 
perlakuan 0.200 serta nilai sig posttest kelompok kontrol 0.092 dan kelompok kontrol 0.200 yang berarti data nilai pretest dan posttest berdistribusi normal (sig >0,05). Data paired $t$ test antar kelompok kontrol dan kelompok perlakuan tercantum pada tabel 1 .

Secara statistik selisih nilai pretest dan posttest pada kelompok perlakuan menunjukkan hasil yang signifikan dengan nilai p 0.000 sedangkan pada kelompok kontrol menunjukkan hasil yang tidak signifikan dengan nilai p 0.014 . Selisih nilai kelompok kontrol dan kelompok perlakuan dianalisis dengan menggunakan uji independent $t$ test dan di dapatkan hasil sig (2tailed) 0.000 yang menunjukkan adanya perbedaan yang signifikan antara kelompok kontrol dan kelompok perlakuan.

Tabel 1. Data paired t test antar kelompok

\begin{tabular}{cccc} 
Kelompok & $\mathrm{N}$ & Mean & Sig. (2- tailed) \\
& & & \\
\hline Kontrol & 47 & -4.18 & 0.014 \\
Perlakuan & 47 & -20.93 & 0.000 \\
\hline *sig. (2-tailed) $<0,05$ terdapat perbedaan yang signifikan
\end{tabular}

\section{PEMBAHASAN}

Hasil dari penelitian ini membuktikan bahwa kelompok yang diberikan materi anatomi menggunakan metode experiential learning hasil belajar anatomi dapat meningkat lebih signifikan. Hal ini terjadi karena mahasiswa kelompok perlakuan melalui tahapan-tahapan pembelajaran metode experiential learning yang terdiri dari tahap concrete experience, reflective observation, abstract conceptualisation dan active experimentation. Tahap concrete experience pada penelitian ini kelompok eksperimen akan diminta untuk menggambar anatomi sistem organa sensuum dalam kelompok kecil (tahap concrete experience). Mahasiswa kemudian saling bertukar gambar yang sudah di buat lalu mereka saling mengoreksi gambar yang sudah dibuat oleh temannya, dari gambar tersebut di amati apa yang masih perlu ditambahkan dan mencocokkan gambar dengan manekin dan cadaver, pada tahap ini mahasiswa bisa melakukan refleksi dari hasil observasi selama praktikum dan mendapatkan umpan balik terstruktur dari dosen sebagai fasilitator (reflective observation). Mahasiswa yang melakukan refleksi memiliki selisih nilai pretest dan posttest yang lebih signifikan secara statistik. Refleksi dilakukan agar mahasiswa mampu menyadari kelebihan dan kekurangan dirinya sendiri. ${ }^{9}$ Refleksi diri disertai dengan pemberian feedback yang terstruktur akan meningkatkan pencapaian, pengembangan pemahaman dan kemampuan mahasiswa dan dapat memotivasi mahasiswa dengan cara memacu dan mengenali usaha mereka dalam proses pembelajaran. ${ }^{10}$ Keberhasilan proses refleksi ini dipengaruhi oleh pemahaman mahasiswa mengenai tujuan keseluruhan dari proses refleksi yang mereka lakukan, motivasi

Vol. 1 No.5 Agustus 2018 
untuk melakukan refleksi, tidak adanya umpan balik dan kurangnya waktu untuk refleksi. ${ }^{11}$

Tahap abstract conceptualization pada penelitian ini mahasiswa diberikan kuliah anatomi oleh pakar dan mahasiswa boleh mengajukan pertanyaan mengenai hal-hal yang masih menjadi keraguan saat mahasiswa melakukan refleksi observasi. Tahapan ini menjadi penting karena mahasiswa akan memiliki suatu pemikiran berdasarkan kesimpulan dari pengalaman yang sudah mereka lalui dan teori yang mereka miliki. ${ }^{12}$ Tahap active experimentation mahasiswa diberikan tugas membuat poster anatomi sistem organa sensuum dalam kelompok kecil, kemudian poster tersebut di presentasikan di hadapan dosen dan temantemannya.Metode ini dianggap baik, efektif dan variatif sehingga mahasiswa tidak merasa bosan untuk belajar dan lebih mudah memahami materi yang diterima. Metode tersebut dapat digunakan untuk menciptakan lingkungan nyata di ruang kelas, sehingga metode experiential learning tetap dapat digunakan untuk pendidikan tahap sarjana. ${ }^{6,13}$

\section{KESIMPULAN}

Penggunaan metode experiential learning mampu meningkatkan hasil belajar anatomi mahasiswa Fakultas Kedokteran. Mahasiswa kelompok perlakuan yang melalui proses refleksi memiliki selisih nilai pretest dan posttest yang lebih signifikan. Pelaksanaan metode experiential learning sangat dipengaruhi oleh keaktifan mahasiswa, peran fasilitator dalam memberikan arahan dan umpan balik, pengetahuan awal yang dimiliki mahasiswa dan lingkungan yang kondusif.

\section{DAFTAR PUSTAKA}

1. Drake, Vogl and Mitchell. Gray's Basic Anatomy. 1st ed. Singapore : Elsevier Churcill Livingstone; 2012.

2. Johnston, A.N.B. Nurse Education in Practice Anatomy for nurses : Providing students with the best learning experience. Nurse Education in Practice. 2010; 10(4): pp.222-226.

3. Johnston, A.N.B., Hammil. J, Barton M.J, Baldwin.S, Percival. J, Williams.G, Salvage. J, Tododrvic. M. Student Learning Styles in anatomy and Physocolgi courses: Meeting the needs of nursing student. Nursing Education In Practice 2015; vol 15.

4. Lempp, H. K. Perceptions of dissection by students in one medical school: beyond learning about anatomy. A qualitative study. Medical Education 2005; 39(3): 318-325.

5. Chan. L.K., Pawlina. W. Teaching Anatomy. A Practical Guide. Swicthzerland: Springer International Publisher; 2015.

6. Kolb, D. Experiential learning: Experience as the source of learning and development. Prentice Hall - PTR; 1984.

7. Sweet, J., Huttly, S., Taylor, I., Effective learning and teaching in medical, dental and veterinary education. Great Britain: Kogan Page Limited; 2003.

8. Kolb, D. Learning styles and learning spaces: A review of the multidisciplinary application of Experiential Learning Theory in higher education. New York: Nova; 2006.

9. Muir, F. The understanding and experience of students, tutors and 
educators regarding reflection in medical education: a qualitative study. Int. J. Med. Educ 2010;1: 61-67.

10. Rowe, A., Wood, L. Student perception and preferences for feedback. Asian Soc. Sci 2008; 4 : 78-88.

11. Sandars, J. The use of reflection in medical education: AMEE Guide No. 44., Med. Teach 2009; 31: 685-695.
12. Fanning, R.M., Gaba, D.M. The role of debriefing in simulation based learning. Simul. Health Care 2007; 2: 1-12.

13. Makmor-Bakry, M., Azmi, N., Ali, A.M. Mannequin-Simulator as a New Teaching and Learning Method in Performance-Based Pharmacotherapy. Indian J. Pharm. Educ. Res. 2013; 47.

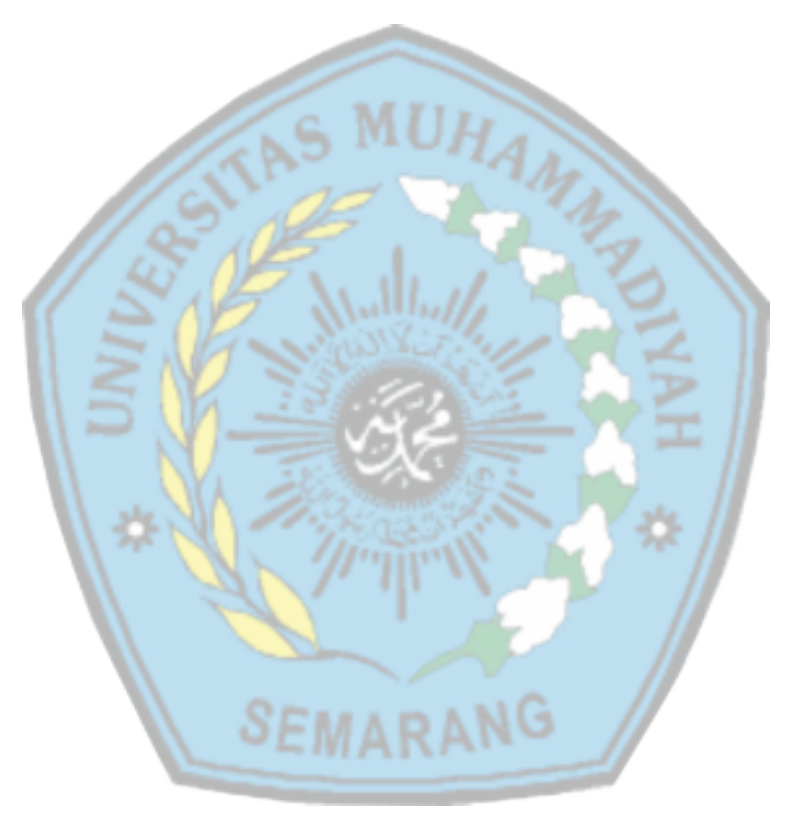

